\title{
Desempenho de novilhas búfalas terminadas em confinamento em resposta ao uso de promotor de crescimento ou de esferas de chumbo no útero
}

\author{
[Buffalo heifer's performance fattened in feedlot in response of the utilization of growth \\ promoter or lead sphere introduced in the uterus]
}

\author{
J.A. Marques ${ }^{1}$, P.T. Iwayama ${ }^{2,5}$, I.N. Prado ${ }^{3,5}$, K.P. Albuquerque ${ }^{2,5}$, \\ V.X. Scomparin ${ }^{2,5}$, W.G. Nascimento ${ }^{4}$ \\ ${ }^{1}$ Centro Integrado de Ensino Superior - Campo Mourão, PR \\ ${ }^{2}$ Aluno de graduação - UEM - Maringá, PR \\ ${ }^{3}$ Departamento de Zootecnia - UEM \\ Av. Colombo, 5790 \\ 87020-900 - Maringá, PR \\ ${ }^{4}$ Aluno de pós-graduação - UEM - Maringá, PR \\ ${ }^{5}$ Bolsista do CNPq
}

\begin{abstract}
RESUMO
Avaliaram-se ganho de peso, ingestão e conversão alimentar de matéria seca e rendimento de carcaça quente de 20 novilhas bubalinas, confinadas, com média de peso de $350 \mathrm{~kg}$ e média de idade de 16 meses. Os animais permaneceram em baias coletivas durante 84 dias e foram alimentadas com silagem de canade-açúcar $+1 \%$ de uréia e concentrado. Os tratamentos foram: VAZ - novilhas vazias, PRC - novilhas com implante de promotor de crescimento e CHU - novilhas com 100 esferas de chumbo introduzidas no útero. $\mathrm{O}$ delineamento foi inteiramente ao acaso com seis repetições no tratamento $\mathrm{VAZ}$ e sete repetições em PRC e CHU. O peso final, ganho médio diário e conversão alimentar da matéria seca foram mais elevados para as búfalas do tratamento PRC, respectivamente, $445,0 \mathrm{~kg} ; 1,2 \mathrm{~kg}$ e $9,7 \mathrm{~kg}$ de MS$/ \mathrm{kg}$ de ganho de peso vivo, em comparação com as do tratamento VAZ, respectivamente, $412,6 \mathrm{~kg} ; 0,9 \mathrm{~kg}$ e $11,4 \mathrm{~kg}$ de $\mathrm{MS} / \mathrm{kg}$ de ganho de peso vivo e as do tratamento $\mathrm{CHU}$, respectivamente, 407,9kg; 0,8kg e 12,2kg de $\mathrm{MS} / \mathrm{kg}$ de ganho de peso vivo. Peso final, ganho médio diário e conversão alimentar da matéria seca das búfalas dos tratamentos VAZ e CHU não diferiram entre si. Para o rendimento de carcaça quente não foi observado efeito entre tratamentos.
\end{abstract}

Palavras-chave: búfala, esferas de chumbo, promotor de crescimento, rendimento de carcaça

\begin{abstract}
A completely randomized design with three treatments and seven replicates was used to evaluate the daily weight gain, dry matter intake, feed:weight gain ratio and hot carcass yield of 20 buffalo heifers averaging $350 \mathrm{~kg}$ and 16 months of age, kept in feed lot for 84 days. Animals were fed on sugar cane silage $+1 \%$ of urea and soybean, corn meal and salt minerals. The treatments were EMP - open heifers GPR - growth promoter implanted heifers and LEA - heifers with 100 lead spheres introduced in the uterus. The GRP animals showed higher body weight, daily weight gain and feed:weight gain ratio (444.0 kg, $1.2 \mathrm{~kg}$ and $9.7 \mathrm{~kg} / \mathrm{kg}$ ) in comparison to EMP animals $(412.6 \mathrm{~kg}$, $9 \mathrm{~kg}$ and $11.4 \mathrm{~kg} / \mathrm{kg}$ ) and LEA animals (407.9, $8 \mathrm{~kg}$ and $12.2 \mathrm{~kg} / \mathrm{kg}$ ), respectively. No significant mean differences between EMP and LEA animals for all the studied traits and no treatment effect on carcass yield were observed.
\end{abstract}

Keywords: buffalo, lead sphere, growth promoter, carcass yield

Recebido em 26 de fevereiro de 2004

Aceito em 2 de junho de 2006

* Autor para correspondência (corresponding author)

E-mail: inprado@uem.br 


\section{INTRODUÇÃO}

Nos sistemas de criação extensivo, semiintensivo ou intensivo, e em determinadas situações, os bubalinos podem produzir de forma semelhante aos bovinos, face aos atributos fisiológicos inerentes à espécie (Vale, 1999).

Em função do grande número de abate de fêmeas (vacas e novilhas de descarte), têm-se feito pesquisas no sentido de corrigir a terminação mais rápida confinando novilhas de descarte (Prado e Moreira, 2002). Segundo Prado e Martins (1999), Marques et al. (2000) e Medroni et al. (2000), fêmeas confinadas e alimentadas $a d$ libitum manifestaram estro nas primeiras semanas de tratamento em função do aporte de energia e proteína (flushing). A manifestação do estro nas primeiras semanas tem efeito negativo sobre ganho de peso, eficiência alimentar e qualidade de carcaça em novilhas Nelore (Prado e Martins, 1999; Medroni et al., 2000 Marques et al., 2000; Prado et al., 2000) ou mestiças ( $1 / 2$ Nelore x $1 / 2$ Angus ou Simental) terminadas em confinamento.

Turin et al. (1997) não observaram, em novilhas mestiças em confinamento e alimentadas à vontade, manifestação de estro, maior ganho em peso e melhor eficiência alimentar com o uso de dispositivos intra-uterinos (DIU). Alcalde et al. (1999), ao trabalharem com novilhas Nelore confinadas e alimentadas à vontade, não observaram manifestação de cio ou alterações na ingestão de matéria seca e no desempenho zootécnico. Os autores observaram que houve migração do DIU em função das ações contráteis e peristálticas do útero.

Em razão dos resultados pouco satisfatórios sobre o desempenho das novilhas e das dificuldades para implantação do DIU, Marques et al. (2001) realizaram um trabalho com novilhas Nelore, com média de peso de $307 \mathrm{~kg}$, alimentadas à vontade, que foram ovariectomizadas para eliminar os efeitos dos hormônios que poderiam alterar o desempenho em confinamento. As novilhas apresentaram maior ganho em peso. No entanto, não houve alteração no rendimento de carcaça e espessura de gordura de cobertura.

Outro mecanismo estudado para impedir a manifestação do estro foi a introdução de pequenas esferas de chumbo no interior do corno uterino, utilizando-se uma pipeta de inseminação artificial (Marques et al., 2001). As novilhas com implante de chumbo apresentaram maior ganho médio diário $(1,0 \mathrm{~kg})$ que as novilhas terminadas sem o implante $(0,8 \mathrm{~kg})$. Não foram observadas alterações no rendimento de carcaça e na espessura de gordura de cobertura. $\mathrm{O}$ maior ganho em peso foi atribuído às alterações hormonais ocasionadas nas novilhas implantadas com esferas de chumbo, pois provocaram várias alterações macroscópicas na parede do útero. Em novilhas búfalas, Albuquerque (2002) observou, mediante cortes histológicos, que esferas de chumbo implantadas no interior do corno útero eram reconhecidas como corpo estranho, desencadeavam uma reação inflamatória e eram expulsas do seu interior por meio da atividade peristáltica.

A terminação de novilhas com prenhez confirmada, como usado rotineiramente pelos pecuaristas, poderia alterar seu perfil hormonal, impedir a manifestação do estro e proporcionar maior desempenho animal, via alterações metabólicas. Todavia, o abate de fêmeas prenhes é considerado pouco ético e, por isso, o uso de outros mecanismos teria duas finalidades: simular a prenhez e, como conseqüência da anterior, evitar uma prática que ocorre com, aproximadamente, $70 \%$ das fêmeas de descarte (abate de fêmeas prenhes). Por outro lado, entre os diversos promotores de crescimento usados, um implante $\left(\right.$ Synovex-H ${ }^{\circledR}$ ) com $200 \mathrm{mg}$ de progesterona e $20 \mathrm{mg}$ de estradiol-17- $\beta$-benzoato aumenta o ganho médio diário e a eficiência alimentar de novilhas de descarte (Ono et al., 1996).

O objetivo deste trabalho foi estudar ganho médio diário, ingestão e conversão alimentar da matéria seca de novilhas bufalinas confinadas por um período de 84 dias, em resposta ao implante de promotor de crescimento ou de esferas de chumbo no interior do útero.

\section{MATERIAL E MÉTODOS}

O trabalho foi realizado na Fazenda Experimental de Iguatemi, no setor de bovinocultura de corte, pertencente à Universidade Estadual de Maringá (UEM). O peso da carcaça quente foi obtido logo após o 
abate das búfalas. Na seqüência, o rendimento de carcaça quente foi calculado entre a razão do peso de carcaça quente e o peso vivo das búfalas, obtido após 14 horas de jejum de sólidos, multiplicado por 100 .

Foram utilizadas 20 novilhas bufalinas da raça Murrah, com peso vivo médio de $350 \mathrm{~kg}$ e com aproximadamente 16 meses de idade. Os animais, criados em sistema extensivo sem qualquer adaptação em comedouros e bebedouros, foram distribuídos ao acaso em três tratamentos, sendo um com seis (VAZ) animais e dois com sete (PRC e CHU). As búfalas foram alojadas em três piquetes de $270 \mathrm{~m}^{2}$ com pouca arborização, mas com cobertura de sombrite.

A dieta completa (silagem de cana-de-açúcar + $1 \%$ uréia, milho em grão quebrado + farelo de soja + sal mineral) foi fornecida duas vezes ao dia (8 e 16 horas). A composição química e percentual das dietas é apresentada na Tab. 1. A dieta foi fornecida à taxa de $2,3 \%$ do peso vivo das búfalas. Segundo Nutrient... (1996), para bovinos de corte, a ração foi calculada para proporcionar ganho de peso vivo médio de 1,0kg/animal/dia. As sobras das rações foram colhidas uma vez por semana para possibilitar os ajustes necessários de consumo.

Tabela 1. Composição química (\%/MS) e percentual (\%/MS) da ração utilizada para novilhas Nelore em confinamento

\begin{tabular}{lccccccc}
\hline Ingrediente & MS & PB & MO & EM* & FDN & FDA & Cinzas \\
\hline Silagem de cana & 25,64 & 7,55 & 94,83 & 2,05 & 40,62 & 43,63 & 5,17 \\
Milho quebrado & 88,41 & 8,80 & 98,96 & 3,25 & 8,37 & 3,94 & 1,04 \\
Farelo de soja & 88,62 & 50,58 & 95,09 & 3,15 & 14,96 & 10,10 & 4,91 \\
Uréia & 98,00 & 262 & - & - & - & - & - \\
Sal mineral $^{1}$ & 95 & - & - & - & - & - & - \\
Ração, \% $^{\text {Nal }}$ & 41,21 & 12,53 & 96,30 & 2,62 & 67,20 & 26,32 & 3,35 \\
\hline
\end{tabular}

Dados obtidos do laboratório de análises de alimentos e alimentação animal do Departamento de Zootecnia/UEM. *Mcal/kg. " ${ }^{1}$ Níveis de garantia por kg de sal mineral: $130 \mathrm{~g} \mathrm{Ca}, 65 \mathrm{~g} \mathrm{P}, 12 \mathrm{~g} \mathrm{~S}, 12 \mathrm{~g} \mathrm{Mg}, 1500 \mathrm{mg} \mathrm{Fe}, 1170 \mathrm{mg} \mathrm{Mn}$, $1300 \mathrm{mg} \mathrm{Cu}, 71 \mathrm{mg}$ Co, $71 \mathrm{mg} \mathrm{I}, 21 \mathrm{mg} \mathrm{Se}, 3200 \mathrm{mg} \mathrm{Zi,} 138 \mathrm{~g} \mathrm{Na}$, 650mg Fl.

Foram estudados três tratamentos: VAZ, novilhas com atividade ovariana; PRC, novilhas com implante de promotor de crescimento $(20 \mathrm{mg}$ de benzoato de estradiol e $200 \mathrm{mg}$ de testosterona); e CHU, novilhas com 100 esferas de chumbo introduzidas no corno uterino com auxílio de uma pipeta de inseminação artificial. Foi realizada palpação retal 30 dias antes do início do experimento, para avaliar as condições reprodutivas do animal. Após período de adaptação de 30 dias, iniciou-se a sincronização de cio pelo protocolo Ovsynch, descrito por Pursley et al. (1995). Aplicaram-se $2 \mathrm{ml}$ de

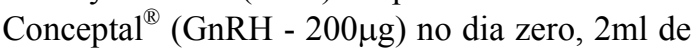
Preloban ${ }^{\circledR}$ (PGF2 $\left.\alpha-150 \mu \mathrm{g}\right)$ sete dias após e $2 \mathrm{ml}$ de Conceptal ${ }^{\circledR}(\mathrm{GnRH}-200 \mu \mathrm{g})$ nove dias após a primeira aplicação. Dezesseis horas após o término deste protocolo, procedeu-se à colocação do promotor de crescimento e das esferas de chumbo. Para colocação do chumbo, o procedimento foi semelhante ao da inseminação artificial. Ao passar a pipeta através da cérvice, a bainha foi direcionada para a extremidade cranial de um dos cornos uterinos, impulsionando-se as esferas contidas na bainha com um expansor. Foram colocadas 100 esferas de chumbo de $4 \mathrm{~mm}$ de diâmetro, previamente esterelizados com álcool $96 \%$. No mesmo dia, as búfalas do tratamento PRC foram implantadas com o promotor de crescimento na orelha direita com $200 \mathrm{mg}$ de testosterona e $20 \mathrm{mg}$ de benzoato de estradiol (Synovex $-\mathrm{H}^{\circledR}$ ).

O experimento teve início no dia 10 de setembro e término no dia 3 de dezembro de 2001. O período de confinamento foi de 84 dias e, ao final, os animais foram abatidos em um frigorífico da região.

O consumo médio de alimento foi determinado semanalmente. Os procedimentos para coleta e análises bromatológicas dos alimentos (matéria seca, proteína bruta, energia bruta, matéria orgânica, fibra em detergente neutro, fibra em detergente ácido e cinzas) seguiram as recomendações para experimentos dessa natureza 
(Silva, 1990). A alimentação foi fornecida para proporcionar sobra de aproximadamente $5 \%$.

$\mathrm{O}$ delineamento experimental foi inteiramente ao acaso com três tratamentos e seis animais para o tratamento VAZ e sete para os tratamentos PRC e CHU. Os dados de ganho de peso e rendimento de carcaça foram analisados pelo SAEG, (Sistema..., 1983) utilizando-se o método dos quadrados mínimos, de acordo com o modelo:

$$
\mathrm{Y}_{\mathrm{ij}}=\mu+\mathrm{t}_{\mathrm{i}}+\mathrm{e}_{\mathrm{i}} \text {, em que: }
$$

$\mathrm{Y}_{\mathrm{ij}}=$ observação no animal $\mathrm{j}$ submetido ao tratamento i;

$\mu=$ constante geral;

$\mathrm{t}_{\mathrm{i}}=$ efeito do tratamento $\mathrm{i} ; \mathrm{i}=1,2$ e 3 ; $\mathrm{e}_{\mathrm{ij}}=$ erro aleatório associado a cada observação
$\mathrm{Y}_{\mathrm{ij}}$.

\section{RESULTADOS E DISCUSSÃO}

O peso vivo médio final e o ganho médio diário (GMD) foram maiores $(\mathrm{P}<0,05)$ para os animais do tratamento PRC em relação aos dos tratamentos VAZ e CHU (Tab. 2). O peso vivo final e o GMD para os animais dos tratamentos VAZ e CHU não diferiram entre si $(\mathrm{P}>0,05)$. Isso revela que o promotor de crescimento foi efetivo ao proporcionar maior ganho de peso.

Tabela 2. Peso inicial e final, ganho médio diário (GMD), ingestão de matéria seca (IMS), conversão alimentar da matéria seca (CAMS), ingestão de matéria seca em percentagem do peso vivo (MS/\%PV) e rendimento de carcaça (RC) de novilhas búfalas em confinamento

\begin{tabular}{lcccc}
\hline Característica & VAZ & CHU & PRC & CV \\
\hline Peso inicial, kg & 346,71 & 348,57 & 356,17 & 13,55 \\
Peso final, kg & $412,57 \mathrm{~b}$ & $407,86 \mathrm{~b}$ & $445,00 \mathrm{a}$ & 18,45 \\
GMD, kg/dia & $0,88 \mathrm{~b}$ & $0,79 \mathrm{~b}$ & $1,18 \mathrm{a}$ & 20,83 \\
IMS, kg/dia & 10,50 & 9,68 & 11,43 & 14,30 \\
CAMS, kg MS/\%PV & $11,39 \mathrm{~b}$ & $12,25 \mathrm{~b}$ & $9,68 \mathrm{a}$ & 16,23 \\
IMS/PV, \% & 2,43 & 2,37 & 2,57 & 15,40 \\
RC, $\%$ & 49,03 & 48,29 & 48,59 & 3,51 \\
\hline
\end{tabular}

Vaz: novilhas vazias, CHU: implante de chumbo no útero, PRC: implante de promotor de crescimento.

Médias na mesma linha, seguidas de letras diferentes, diferem entre si $(\mathrm{P}<0,05)$ pelo teste Tukey.

CV: coeficiente de variação.

O uso de promotor de crescimento proporcionou maior ganho de peso das búfalas do grupo PCR em relação ao VAZ e ao CHU. Efeito positivo do promotor de crescimento, como usado neste trabalho, sobre o ganho em peso foi demonstrado por Ono et al. (1996) em ruminantes. Todavia, deve-se salientar que a legislação brasileira não permite o uso de substâncias exógenas para promover ganho de peso e melhora na eficiência alimentar em ruminantes terminados em confinamento ou em pastejo.

Turin et al. (1997), em novilhas que receberam dispositivo intra-uterino (DIU) em plástico, não observaram manifestação de estro, mas verificaram maior ganho em peso nas novilhas mestiças, terminadas em confinamento e alimentadas à vontade, enquanto Alcalde et al. (1999), em novilhas Nelore confinadas e alimentadas ad libitum, não observaram manifestação de cio nem alteração na ingestão de matéria seca e/ou modificação no desempenho zootécnico dos animais. Os autores relataram migração do DIU para diversas partes da cavidade abdominal, provavelmente em razão das ações contráteis e peristálticas do útero. Marques et al. (2001), ao trabalharem em condições semelhantes às deste trabalho, mas com novilhas mestiças ( $1 / 2$ Nelore x $1 / 2$ Angus), com ganho médio diário próximo a $1 \mathrm{~kg}$, obtiveram ganhos superiores para os animais implantados com esferas de chumbo. No presente caso, a ausência de efeito positivo da implantação do chumbo pode ter ocorrido em razão da expulsão das esferas de chumbo de dentro do útero dos animais. Em novilhas búfalas, Albuquerque (2002) observou em cortes histológicos que as esferas de chumbo implantadas no interior do útero eram reconhecidas como corpo estranho, desencadeavam reação inflamatória e eram expulsas do seu interior em resposta à atividade peristáltica. 
Observou-se pouca alteração de comportamento das búfalas durante o período experimental. Deve-se mencionar que o experimento foi realizado no segundo semestre do ano, quando, teoricamente, a atividade reprodutiva é menor (Zicarelli, 1994). Os animais apresentaram atividade ovariana normal, comprovada por palpação retal e avaliação histológica (folículos em crescimento, ovulação e presença de corpo lúteo) após o abate.

O ganho médio diário $1 \mathrm{~kg}$ foi satisfatório para animais dessa categoria e idade. Velloso et al. (1994) observaram ganho médio diário de $1 \mathrm{~kg} /$ dia para búfalos da raça Mediterrânea com peso vivo inicial de $328,7 \mathrm{~kg}$ e 18 meses de idade, terminados em confinamento durante 112 dias, após receberem dieta à base de silagem de sorgo, milho com palha e sabugo, grãos de soja crua e mistura mineral. Moletta e Restle (1994), ao trabalharem com bubalinos da raça Mediterrânea, utilizando relações de volumoso: concentrado de $75: 25,65: 35$ e 55:45, obtiveram ganhos de peso de $1,1,2$ e $1,2 \mathrm{~kg} /$ dia, respectivamente. Silva et al. (1994), em búfalos da raça Murrah em confinamento, alimentados na relação volumoso: concentrado de 75:25, base da matéria seca, observaram ganho em peso de 1,2kg/dia. Ainda, búfalos da raça Mediterrânea confinados, recebendo dieta na relação volumoso: concentrado de 50:50, apresentaram ganhos de $1,3 \mathrm{~kg} / \mathrm{dia}$ (Jorge et al., 1997). Mais recentemente, Franzolin et al. (2001) obtiveram ganho de peso de $0,9 \mathrm{~kg} /$ dia para búfalos da raça Mediterrânea terminados em confinamento por um período de 140 dias. Esses dados mostram que o potencial de ganho em peso diário de búfalos, terminados em confinamento, varia entre 1 a 1,3kg/dia. O ganho médio diário obtido neste experimento, em geral, foi inferior aos ganhos citados na literatura, mas deve-se enfatizar que foram usadas búfalas jovens $(350 \mathrm{~kg}$ de peso vivo e idade de 16 meses), cujo potencial de crescimento e acabamento é menor que o de machos.

A ingestão de MS foi semelhante $(\mathrm{P}>0,05)$ para os três tratamentos (Tab. 2). Turin et al. (1997), ao trabalharem com novilhas mestiças, e Alcalde et al. (1999), com novilhas Nelore, não observaram efeito da introdução de material plástico (DIU) nos cornos uterinos sobre a ingestão diária de matéria seca. Velloso et al. (1994) observaram ingestão de 8kg/animal/dia de
MS para búfalos com peso vivo inicial de $328,7 \mathrm{~kg}$ e final de $442,5 \mathrm{~kg}$ terminados em confinamento por um período de 112 dias. Resende et al. (1995) verificaram consumo de $9 \mathrm{~kg} /$ dia de MS para búfalos da raça Mediterrânea com peso vivo de $328 \mathrm{~kg}$ e idade média de 24 meses alimentados na proporção volumoso: concentrado de 50:50.

A ingestão de MS (kg/dia), observada neste experimento, foi superior às encontradas na literatura. Todavia, a parte volumosa da ração era constituída de silagem de cana-de-açúcar, que pode ter proporcionado aumento no consumo de MS em razão do seu menor aproveitamento.

A conversão alimentar da matéria seca (CAMS) foi melhor $(9,7=\mathrm{P}<0,05)$ para os animais do tratamento $\mathrm{PRC}$, em comparação àqueles dos tratamentos VAZ $(11,4)$ e $\mathrm{CHU}(12,2)$, mas não foi observada diferença $(\mathrm{P}>0,05)$ entre esses dois últimos tratamentos. Alcalde et al. (1999) não observaram efeito do uso de DIU em novilhas Nelore terminadas em confinamento, alimentadas ad libitum, sobre a conversão alimentar da MS.

Com exceção do tratamento PRC, a conversão alimentar da MS foi pior em comparação aos valores encontrados na literatura, que variaram de 7,1 a $9,8 \mathrm{~kg} \mathrm{MS} / \mathrm{kg}$ de ganho em peso vivo (Velloso et al., 1994; Moletta e Restle, 1994; Franzolin et al., 2001). A pior conversão alimentar observada neste experimento pode estar relacionada ao tipo de silagem utilizada (silagem de cana-de-açúcar tratada com 1\% de uréia).

Os valores de ingestão de matéria seca, em porcentagem do peso vivo (IMS/PV), foram semelhantes $(\mathrm{P}>0,05)$ para os três tratamentos e variaram de $2,4 \%$ para os tratamentos VAZ e CHU a 2,6\% para o tratamento PRC. Velloso et al. (1994) observaram ingestão de $\mathrm{MS} / \% \mathrm{PV}$ da ordem de $2,1 \%$ para búfalos terminados em confinamento e alimentados à vontade. Ingestão de $\mathrm{MS} / \% \mathrm{PV}$ semelhante à deste trabalho foi encontrada por Jorge et al. (1997) em búfalos da raça Mediterrânea, terminados em confinamento, e que receberam dieta na relação volumoso: concentrado de 50:50. Outros autores encontraram valores de 2,1 a 2,3kg de MS para $100 \mathrm{~kg}$ de peso vivo (Moletta e Restle, 1994; Franzolin et al., 2001). Os valores deste trabalho, 
ligeiramente acima em relação aos observados na literatura, podem estar relacionados ao tipo e qualidade de volumoso fornecido. A cana-deaçúcar in natura, quando administrada adequadamente, provoca aumento do consumo de MS em razão da sua aceitabilidade pelos animais.

Apesar de o ganho em peso ter sido superior para os animais do tratamento $\mathrm{PRC}$, não houve diferença $(\mathrm{P}>0,05)$ entre os tratamentos para rendimento de carcaça quente. $\mathrm{O}$ rendimento médio de carcaça foi de $48,6 \%$. A semelhança nas respostas pode ter ocorrido, possivelmente, porque os animais do tratamento PRC apresentaram aumento de peso de partes não avaliadas (couro, cabeça, órgãos internos) quando se estudou o rendimento de carcaça. Isto ocorre, sobretudo, com os órgãos internos, quando os animais são tratados com promotores de crescimento exógeno. Jorge (1993) afirmou que o rendimento de carcaça foi influenciado pelo peso da cabeça, couro e trato gastrintestinal, principalmente em bubalinos. Todavia, deve-se destacar o baixo rendimento de carcaça quente obtido neste experimento. Moletta et al. (1987) encontraram rendimento de carcaça de 48,6\% em búfalos da raça Mediterrânea terminados em confinamento. Rendimentos superiores foram encontrados por Muller et al. (1994), 53,1\%, Gazetta et al. (1995), 52,6\%, Mattos et al. (1997), 52,4\%, Franzolin et al. (1988) e Franzolin e Silva (2001) em búfalos da raça Mediterrânea, terminados em confinamento com diferentes níveis de energia na ração. Deve-se mencionar que o rendimento de carcaça, por se tratar de medida relativa, está sujeito a erros relacionados aos sistemas de limpeza empregados nas diversas plantas de abate no país. Isso decorre do maior ou menor grau de exigência do abatedouro no momento da esfola, evisceração e limpeza da carcaça.

\section{CONCLUSÕES}

O uso de promotor de crescimento, neste experimento $200 \mathrm{mg}$ de testosterona e $200 \mathrm{mg}$ de benzoato estradiol, pode ser recomendado, pois proporciona aumento em ganho de peso diário e melhora a conversão alimentar de novilhas búfalas, sem, contudo, aumentar o consumo de matéria seca e o rendimento de carcaça, desde que haja permissão da legislação brasileira. A introdução de esferas de chumbo no corno uterino não apresenta resultados satisfatórios sobre ganho de peso, consumo de matéria seca e rendimento de carcaça.

\section{REFERÊNCIAS BIBLIOGRÁFICAS}

ALBUQUERQUE, K.P. Atividade ovariana $e$ níveis plasmáticos de metabólitos e hormônios de novilhas bubalinas terminadas em confinamento em função do promotor de crescimento ou esferas de chumbo no útero. 2002. 41f. Trabalho de Graduação (Zootecnia) - Universidade Estadual de Maringá, Maringá, PR.

ALCALDE, C.R.; PRADO, I.N.; GADOI, Y.A. et al. Avaliação do desempenho de novilhas Nelore implantadas com dispositivo intra-uterino (DIU) recebendo ou não mistura mineral. Acta Scent., v.21, p.633-636, 1999.

FRANZOLIN, R.; SILVA, J.R. Níveis de energia na dieta de bubalinos em crescimento alimentados em confinamento. 2. Características de carcaça. Rev. Bras. Zootec., v.30, p.1880-1885, 2001.

FRANZOLIN, R.; SILVA, J.R.; OCAMPOS, D. Níveis de energia na dieta de bubalinos em crescimento alimentados em confinamento. 1 . Desempenho e bioquímica de nutrientes sangüíneos. Rev. Bras. Zootec., v.30, p.1872-1879, 2001.

FRANZOLIN, R.; VELLOSO, L.; SILVA, J.R. Características da carcaça de búfalos alimentados com três níveis de energia em confinamento. In: REUNIÃO ANUAL DA SOCIEDADE BRASILEIRA DE ZOOTECNIA, 35., Botucatu. Anais.... Botucatu, SBZ, p.395-397. 1988.

GAZETTA, M.C.R.R.; ITURRINO, R.P.S.; CAMPOS, B.E.S. et al. Avaliação corporal de búfalos (Bubalus bubalis) e bovinos Nelore (Bos indicus) terminados em confinamento. Bol. Ind. Anim., v.52, p.77-86, 1995.

JORGE, A.M. Ganho de peso, conversão alimentar $e$ características de carcaça de bovinos $e$ bubalinos. 1993. Dissertação (Mestrado em Zootecnia) - Universidade Federal de Viçosa, Viçosa, MG.

JORGE, A.M.; FONTES, C.A.A.; FREITAS, J.A., et al. Ganho de peso e de carcaça, consumo e conversão alimentar de bovinos e bubalinos, abatidos em dois estágios de maturidade. Rev. Bras. Zootec., v.26, p.806-812, 1997. 
MARQUES, J.A.; PRADO, I.N.; NASCIMENTO, W.G. Avaliação do desempenho de novilhas mestiças em diferentes condições reprodutivas confinadas. In: REUNIÃO ANUAL DA SOCIEDADE BRASILEIRA DE ZOOTECNIA, 38., 2001, Piracicaba. Anais... Piracicaba, SBZ, 2001.

MARQUES, J.A.; PRADO, I.N.; ZEOULA, L.M. et al. Avaliação da mandioca e seus resíduos industriais em substituição ao milho no desempenho de novilhas confinadas. Rev. Bras. Zootec., v.29, p.1528-1536, 2000.

MATTOS, J.C.A.; JORGE, A.M.; NOGUEIRA, J.R. Características de carcaça de búfalos Mediterrâneo (Bubalus bubalis) e bovinos Nelore (Bos indicus) terminados em confinamento. In: REUNIÃO ANUAL DA SOCIEDADE BRASILEIRA DE ZOOTECNIA, 34., 1997, Juiz de Fora. Anais... Juiz de Fora, SBZ, 1997. v.1, p.346-348.

MEDRONI, S.; PRADO, I.N.; NASCIMENTO, W.G. et al. Efeito da combinação de dietas contendo milho ou triticale e farelo de soja ou levedura sobre o desempenho de novilhas nelore terminadas em confinamento. Acta Scient., v.22, p.787-791, 2000.

MOLETTA, J.L.; RESTLE, J. Feedlot performance of cattle and buffalo steers. In: WORLD BUFFALO CONGRESS, 5., São Paulo. Proceedings... São Paulo, 1994. v.2, p.130-132.

MOLLETA, J.L.; RESTLE, J.; TOWNSEND, R.M.; MARTINS, J.D. Características de carcaça de quatro grupos genéticos de bovídeos. In: REUNIÃO ANUAL DA SOCIEDADE BRASILEIRA DE ZOOTECNIA, 24., Brasília. Anais... Brasília, SBZ, 1987. p.274.

MULLER, L.; AGUIRRE, L.F.; RESTLE, J. et al. Carcass and meat quality of cattle and buffalo. In: WORLD BUFFALO CONGRESS, 5., São Paulo. Procedings... São Paulo 1994. p.110-112.

NUTRIENTS requirements of beef cattle Washington: NRC, 1996. 242p.

ONO, Y.; SOLOMON, M.B.; ELSASSER, T.H. et al. Effects of synovex-S and recombinant growth PRCmone (Somavubove) on growth responses of steers: II. Muscle morphology and proximate composition of muscles. J. Anim. Sci., v.74, p.29292934, 1996.

PRADO, I.N.; MARTINS, A.S. Efeito da substituição do farelo de algodão pelo farelo de canola no desempenho de novilhas Nelore confinadas. Rev. Bras. Zootec., v.28, p.1390-1396, 1999.

PRADO, I.N.; MARTINS, A.S.; ALCALDE, C.R. et al. Desempenho de novilhas alimentadas com rações contendo milho ou casca de mandioca como fonte energética e farelo de algodão ou levedura como fonte protéica. Rev. Bras. Zootec., v.29, p.278-287, 2000 .

PRADO, I.N.; MOREIRA, F.B. Suplementação de bovinos no pasto $e$ alimentos usados na bovinocultura Maringá: EDUEM, UEM, 2002. $162 \mathrm{p}$.

PURSLEY, J.R.; MEE, M.O.; WILTBANK, M.C. Synchronization of ovulation in dairy cows using $\mathrm{PGF}_{2 \alpha}$ and GnRH. Theriogenology, v.44, p.915923, 1995.

RESENDE, F.D.; QUEIROZ, A.C.; FONTES, C.A.A. et al. Fibra em detergente neutro versus fibra em detergente ácido na formulação de dietas para ruminantes. Rev. Bras. Zootec., v.24, p.342350. 1995.

SILVA, D.J. Análise de alimentos. 2.ed. Viçosa: Imprensa Universitária, 1990. 166p.

SILVA, M.E.T.; FLEMMING, J. S.; MARTINEZ, J.L. Desempenho de búfalos confinados com dietas com diferentes relações de volumoso e concentrado. 1. Confinamento. In: REUNIÃO ANUAL DA SOCIEDADE BRASILEIRA DE ZOOTECNIA, 33., 1994, Juiz de Fora. Anais..., Juiz de Fora, SBZ, 1994. v.1, p.314-316.

SISTEMA de análises estatísticas e genéticas. SAEG. Viçosa: UFV, 1983. 68p.

TURIN, E.M.; NAGLE, C.A.; LANHOZ, M. et al. Effects of a copper-bearing intrauterine device on the ovarian function, body weight gain and pregnancy rate of nulliparous heifers. Theriogentelogy, v.47, p.1327-1336, 1997.

VALE, W.G. Perspectivas da bubalinocultura no Brasil e na América Latina. In: SIMPÓSIO PAULISTA DE BUBALINOCULTURA, 1., Jaboticabal. Anais..., Jaboticabal, SP, 1999. p.2-26.

VELLOSO, L.; ACHALCH, E.; FRANZOLIN NETO, R. et al. Desempenho comparativo de zebuínos Nelore e bubalinos Mediterrâneo em regime de confinamento. Rev. Bras. Zootec., v.23, p.236-241, 1994.

ZICARELLI, L. Management in different environmental condition. Buffalo J., v.10, suppl. 2, p.17-38, 1994. 